\title{
UNA PINTURA DE DOMENICO CRESTI EN BURGOS
}

Entre las pinturas conservadas en el Museo de Burgos, procedentes de los fondos de Desamortización ${ }^{1}$, se encuentra una a la que tradicionalmente se le ha venido denominado, desde su ingreso en las colecciones de esta institución, con el título de San Pedro bautizando a una noble romana y que, en origen, formó parte de las riquísimas colecciones de pintura del monasterio benedictino de San Salvador de Oña ${ }^{2}$. La existencia en el altar mayor de la iglesia de romana de Santa Prisca de un lienzo semejante al burgalés nos ha permitido no sólo poder realizar la atribución de la pintura a Domenico Cresti «il Passignano» sino también hacer una correcta identificación iconográfica.

El Passignano (1559-1638) es uno de los mejores exponentes de la pintura tardomanierista toscana. Se formó en el ámbito de pintores como Machietti, Naldini, Stradano... ${ }^{3}$. Muy pronto, entró en contacto con Federico Zucaro colaborando con él, intensamente, en varios importantes proyectos. En 1580, estaba en Roma trabajando en la capilla Paolina en el Vaticano. También colaborará en la culminación de la decoración de la cúpula de la Catedral de Santa María dei Fiori de Florencia. Con este pintor estuvo en Venecia, en 1583, permaneciendo en esa ciudad hasta 1589 , siendo especialmente importante este viaje en su carrera pues le permitió impregnarse del gusto colorista veneciano que caracterizará a buena parte de su producción posterior. En el primer decenio del siglo xvII, su fama será tan notable que los encargos de importantes personajes de la Roma del momento serán continuos, hasta tal punto que tuvo que trasladar a la Ciudad Eterna su residencia contribuyendo a difundir la estética del «manierismo reformado». En esta urbe trabajará por encargo de Clemente VIII y Paulo V en las iglesias de San Giovanni dei Fiorentini y Santa Maria Maggiore. En 1604, recibió el encargo de Maffeo Barberini (futuro Urbano VIII) de decorar la capilla familiar en la iglesia de Sant'Andrea della Valle donde realizó, en 1613, el cuadro del altar mayor. En estos años iniciales del siglo, supo combinar, de manera perfecta, el dimamismo cromático adquirido en Venecia con un naturalismo descriptivo de carácter realista. Regresó a Florencia en 1616 donde murió en 1638, aunque entre 1624 y 1626 se le vuelve a documentar en Roma trabajando para el papa Urbano VIII en San Pedro. En los últimos años de su actividad productiva, desarrolló un cierto abandono de las fórmulas academicistas y cada vez se detecta más un acercamiento a los postulados claroscuristas de Caravaggio ${ }^{4}$, con quien debió tener intensos contactos en su estancia en la Ciudad Eterna, pues ambos maestros tuvieron mecenas comunes como monseñor Massini.

La pintura que preside el altar mayor de la iglesia romana de Santa Prisca fue realizada en torno a 1600. Unos años antes de esa fecha y con motivo de la preparación del Jubileo que iba a celebrarse en ese año, se desarrolló, en buena parte de las iglesias romanas, una intensa actividad de renovación y ornato. Benedetto Giustinianni, que había sido nombrado cardenal de Santa Prisca en 1599, se volcó generosamente en la iglesia del Aventino que estaba bajo su

\footnotetext{
${ }^{1}$ La sección de Bellas Artes del Museo de Burgos tiene su origen en las obras procedentes de los monasterios y conventos desamortizados burgaleses (Varios Autores: Elorza Guinea, J.C., Castillo Iglesias, B. y Negro Cobo, M.: 150 años del Museo de Burgos, Burgos, 1996, pp. 36-51).

${ }^{2}$ El Monasterio de San Salvador de Oña poseyó una de las más ricas colecciones de pintura de la provincia de Burgos. Tras la Desamortización ingresaron, en el Museo Provincial, en 1840, 16 cobres, a los que siguieron, en 1845, 139 cuadros más. Entre estas pinturas debían hallarse la que nos ocupa, así como el cuadro La Ultima Comunión de San Benito, inspirado en La Última Comunión de San Jerónimo del Domenichino, ambas de orígenes italianos (OSABA Y RUIZ DE ERENCHUN, Basilio: Historial del Museo Arqueológico de Burgos, Burgos, 1960, p. 19).

3 Voss, Hermann: La pittura del Tardo Rinascimento a Roma e a Firenze, Donzelli Editori, Roma, 1994; Nisman, Joan Lee: Domenico Cresti “il Pasignano" 1559-1638. A tuscan painter in Florence and Rome, Columbia University, 1979.

${ }^{4}$ Sobre el desarrollo del caravaggismo se puede acudir al catálogo Strinati, Claudio y Vodret, Rosella: Caravaggio $e$ i suoi. Percorsi caravaggeschi in Palazzo Barberini, Electa Napoli, 1999.
} 
protección ${ }^{5}$. Entre las labores que se llevaron a cabo hacia 1600 destacan la construcción de una nueva fachada, diseñada por Carlo Lombardi y la decoración interna de la iglesia. En estos últimos trabajos intervinieron el Passignano y su discípulo Anastasio Fontebuoni ${ }^{6}$. Es difícil determinar con exactitud por qué el cardenal genovés eligió a dos pintores florentinos para estas labores. Abromson ha sugerido que quizá el interés de Giustiniani por estos artistas se debiera al hecho de que pudo conocer la obra que Fontenbuoni estaba realizando para el cardenal Pompeo Arrigoni en su iglesia titular de Santa Balbina y así entrar en contacto con este pintor y su maestro ${ }^{7}$. Sabemos que tanto Benedetto Giustiniani como su hermano Vicenzo eran dos de los más importantes coleccionistas de arte de la Roma del momento y que tenían entre las obras de sus colecciones dos pinturas del Passignano ${ }^{8}$. Creemos que el inicio de la relación entre cardenal y el pintor florentino se produjo a través del encargo de la pintura del altar mayor de Santa Prisca y que las obras del mismo, que formaron parte de la pinacoteca del cardenal, ingresaron en ella a raíz del descubrimiento de su producción por este hecho. El Passignano no llegó a Roma hasta 1602, por lo que la pintura de Santa Prisca le sería encargada en Florencia. Se conserva un grupo de dibujos contemporáneos que representan el bautismo de santa Prisca, lo cual nos indica que debió existir un concurso para el encargo de esta obra. Hay dos dibujos de Cigoli, uno atribuido a Tempesta, otro a Baglione y el del Passignano ${ }^{9}$.

La pintura del altar mayor de Santa Prisca es un óleo sobre lienzo de $250 \times 175 \mathrm{cms}$. que, como ya hemos señalado, debió pintarse en torno a 1600. Se trata de una obra muy sencilla, perfectamente encuadrable en las coordenadas estéticas de la Contrarreforma, en la que aparecen ya superados, definitivamente, todos los excesos formales de la pintura del primer manierismo y donde lo que predomina es una clara búsqueda del decoro, entendiéndose por tal la perfecta adecuación de lo visible a lo narrado, siempre tendiéndose a la incitación a la devoción. La composición resulta sencilla. Los dos protagonistas se hallan en relación compositiva formando una marcada diagonal que aparece como eje de la escena. Espacialmente el lienzo se organiza en tres planos superpuestos. En el primero, hallamos a la santa, arrodillada sobre una pequeña grada, recibiendo el bautismo y la figura infantil de un acólito, también de rodillas, sosteniendo un libro litúrgico y que vuelve su cabeza hacia el espectador. En un segundo plano encontramos la figura de san Pedro que dirige su mirada sobre la santa. Con su mano derecha, acercada a la cabeza de la misma, procede al bautismo, mientras que con la izquierda pasa las hojas del libro. Al mismo nivel del santo aparece una figura femenina en reverente actitud de contemplación de la escena. Por fin, en el fondo, hallamos dos grupos de personajes, un par de mujeres y un par de hombres, situados de forma simétrica, que asisten al acontecimiento. En la parte derecha del lienzo se abre una perspectiva, a través de un arco, que dota de profundidad a la composición. El componente sobrenatural se halla presente en la escena por medio de un rompimiento de cielo, en la zona superior, en el que podemos ver dos ángeles en torno a un haz luminoso. Es precisamente de aquí de donde procede la fuente de luz esencial de la obra. Como en otros trabajos del pintor una suave luz dorada flota en el espacio y permite la iluminación de los personajes que quedan destacados, sobre todo, en los primeros planos, mientras que en el último se muestran

\footnotetext{
${ }^{5}$ SAngiorgi, Geremia: Santa Prisca e il suo mitreo, Edizioni Roma, Roma, 1968. La iglesia de Santa Prisca, en el monte Aventino, se construyó, en los primeros siglos del cristianismo sobre la casa de San Aquila y Santa Prisca, padres de santa Priscila. Tradicionalmente se ha considerado a este templo como uno de los lugares cristianos más antiguos de Roma pues se cree que fue una iglesia doméstica en la que predicó el propio san Pedro.

${ }^{6}$ Baglioni, Giovanni: Le vite dei pittori et architetti dal pontificato di Gregorio XIII del 1572 in fino a'tempi di papa Urbano Ottavo nel 1642, Roma, 1642. (Edición de Valerio Mariani. Istituto d'Archeologia e Storia dell'arte, Roma, 1935. pp. 135 y 166).

7 Abromson, Morton C.: Painting in Rome during the Papacy of Clemente VIII: A documentated study, Ph. D. D. Dissertattion, Columbia University, New York, 1976, pp. 162-163.

${ }^{8}$ Fellini, Pietro Martire: Trattato nuovo delle cose maravigliose dell'alma cittá de Roma, Roma, 1610, p. 146.

${ }^{9}$ Gabinete de Dibujos de los Uffizi. Número 217 F. Lápiz negro. 28,3 X 19,5 cms.
} 


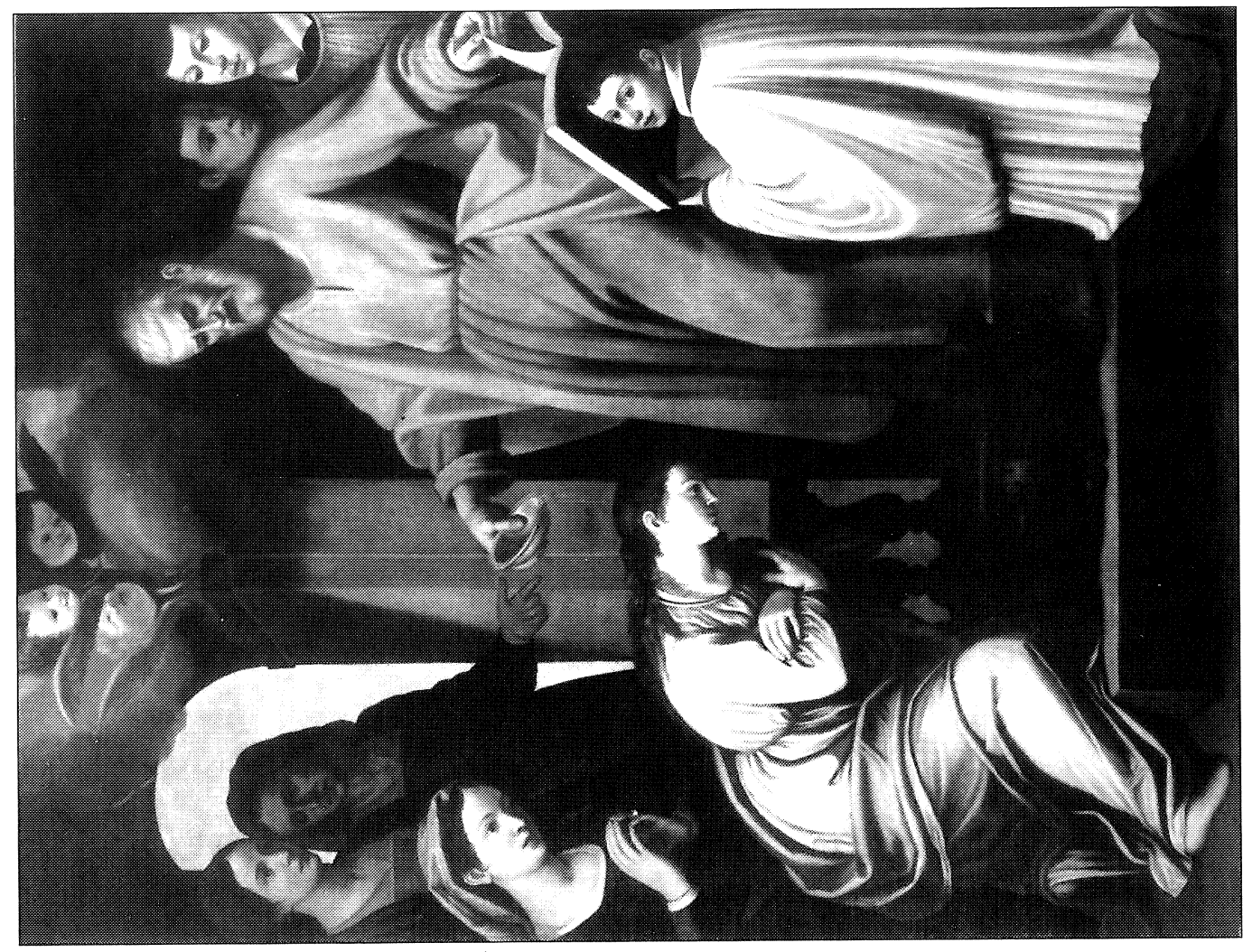

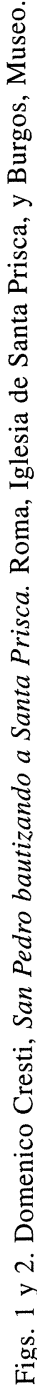

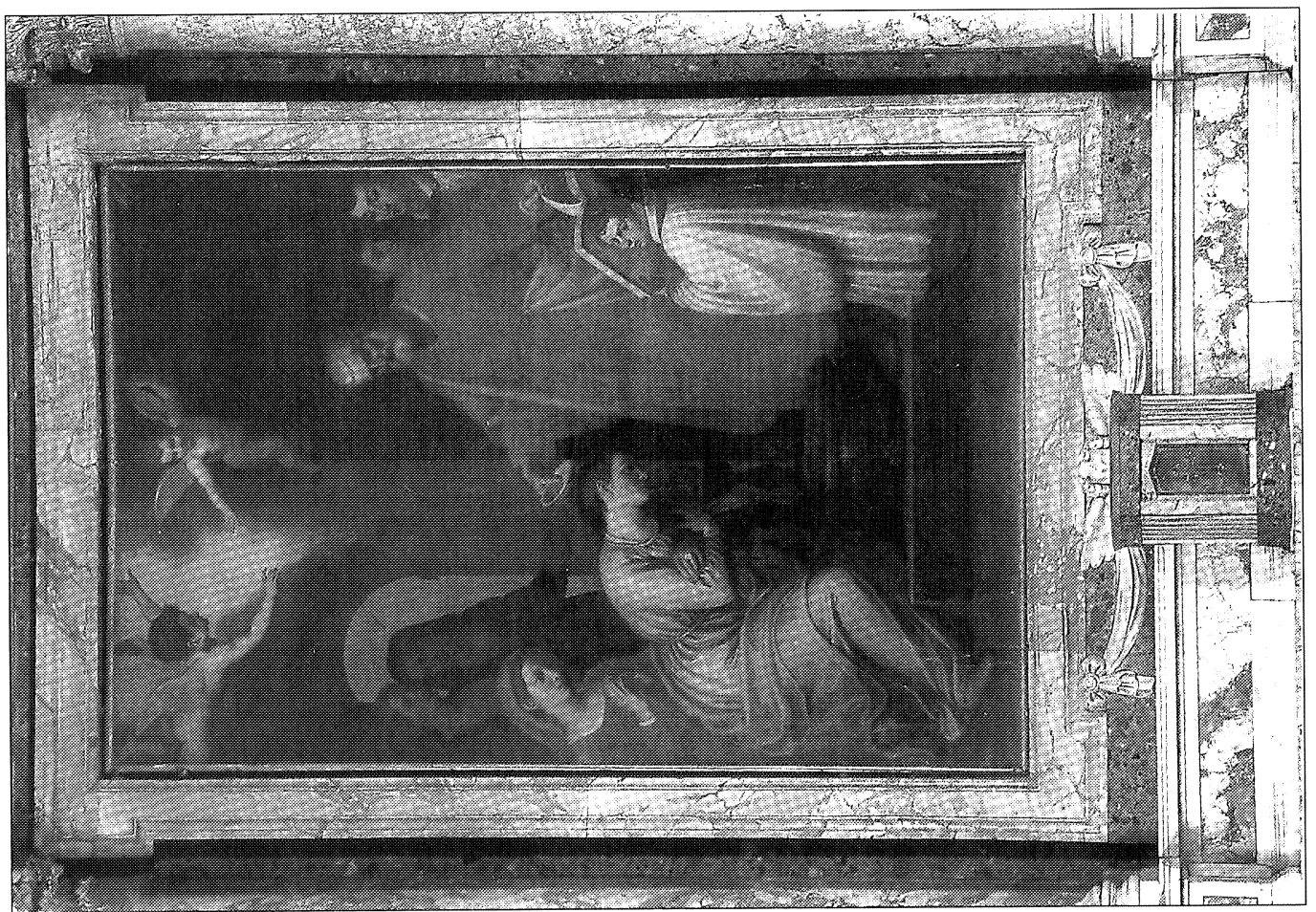


algo más diluidos en un ambiente más oscuro. La utilización de la luz, unida a una concepción monumental de las figuras, dota a las mismas de unos valores claramente escultóricos, sumamente característicos de la época. La gama cromática empleada destaca por la utilización de azules, rojos y rosas, estos últimos de ascendencia tardomanierista.

El lienzo burgalés, custodiado en el Museo de Burgos, es también una pintura sobre óleo que presenta casi las mismas dimensiones que el romano $(240 \times 175 \mathrm{cms}$.). Como ya señalamos, anteriormente, esta pintura estuvo ubicada en el Monasterio de San Salvador de Oña hasta que pasó a formar parte de los fondos de este museo tras la Desamortización. Desconocemos cómo se produjo la llegada de esta pieza a este centro monástico ${ }^{10}$. Sin duda, la importancia que tuvo el monasterio a lo largo de la Historia le facilitó la adquisición de piezas no sólo de maestros españoles sino también foráneos ${ }^{11}$. Quizá la llegada de este lienzo a Oña estuvo en relación con la de alguna reliquia de santa Prisca. Hemos de recordar que en los últimos años del siglo xvi y en el siglo xvir el tráfico de reliquias en el mundo católico vivió un notable resurgimiento, a raíz de los favorables dictámenes trentinos a su culto, sobre todo de aquéllas vinculadas a santos y santas de los primeros momentos del cristianismo.

Creemos que esta obra salió del propio taller del Passignano y que probablemente se realizó o bien por el propio maestro o por algún oficial destacado en el mismo. La calidad es sumamente pareja en el cuadro romano y en el burgalés. La definición del dibujo, el tratamiento de los rostros y manos, el de los paños y la disposición de todos los elementos resultan semejantes. Las únicas diferencias sustanciales que existen entre ambas pinturas las hallamos en la forma de realizar el rompimiento de cielo y en las tonalidades que en el caso de la obra de Burgos resultan ligeramente más apagadas aunque la gama cromática, en ambos lienzos, es la misma, lo que nos ratifica en la idea de que nos encontramos ante una obra salida del mismo ámbito que la romana.

René Jesús Payo Hernanz Universidad de Burgos

\section{UN RETRATO DE AGUSTÍN ESTEBAN COLLANTES, MINISTRO DE FOMENTO, POR JUSTO MARÍA DE VELASCO Y GALAMINO}

Dentro del convento de San Francisco de Palencia ${ }^{1}$, en unas dependencias anejas a lo que fue la sede de la Sociedad Económica, arrinconado, se encuentra un lienzo sin firmar (115 $\times$ $87 \mathrm{~cm}$.), en buen estado (apenas una rotura y suciedad), que desde 1887 lució en el salón de actos de la ilustrada corporación. Y es que en aquella fecha, cumpliendo con una de las mandas testamentarias de Justo María de Velasco, el pintor entrega a los Amigos del País un retrato de Esteban Collantes ${ }^{2}$.

\footnotetext{
${ }^{10}$ La primera mitad del siglo XVII es una época de gran dinamismo constructivo y de renovación de los bienes muebles en este importante centro monástico. La importancia del monasterio, panteón real, sin duda, posibilitó no sólo los contactos del mismo con la Corte sino también con Roma de donde, sin duda, procede la pintura.

11 Herrera Oria, Enrique: Oña y su Real Monasterio hoy Colegio de Padres Jesuitas según la descripción inédita del monje de Oña fray Í̃igo de Barreda, Madrid, 1917.

1 Agradezco a doña Ana Isabel Barreda haberme confiado su existencia, así como también al padre Semprún la amabilidad con la que me facilitó el acceso y estudio del cuadro.

${ }^{2}$ El Diario Palentino (10-X-1887) y Archivo Histórico Provincial de Palencia. Sección Protocolos, legs. 16.732, 16.737 y 16.964 (signaturas antiguas).
} 